ponents play in any given case. Similarly, the employment of remedies, so seldom required that professedly the Codex does not expect to find then in the shops, must be to a great extent problematical, as their qualities cannot have been, in the majarity of cases, much tested. In the new edition, whenever it is forthcoming, $I$ hope to find rather a reflection of modern science, than a collection of formulæ representing in some cases the relics of empiricism, in others the art of ringing changes on tisanes and syrups.

\section{REPORT OF A CASE OF HYDROPHOBIA.*}

\section{BY THOMAS COSSAR, M.D., Hurworth, Darlington.}

OF all the diseases to which human kind is heir, few have, at different epochs, elicited greater attention than hydrophobia. Amongst the ancient writers upon it, we have Celsus, Dioscorides, and Galen; whilst in more modern times, Cullen, Fothergill, and Bardsley have contributed largely to swell our knowledge on the subject.

As at the present time it appears to be more than usually prevalent, and a case happening recently to have come under my observation, I hope it may not be altogether wasting the time of this Northern Branch of the British Medical Association, in simply giving the short history from the period of the patient's coming under medical observation, until the fatal termination, about forty hours.

On April 21st, at six in the morning, a former assistant of mine was hastily summoned to visit Humphrey Lee, residing near the beautiful village of Middleton-one-Row, four miles from Darlington. He was 39 years of age, and a gardener by occupation. In his garden, which was much infested with rabbits, he had traps set to catch those vermin. On the morning of March 4th, on going into his ground, he found a strange dog entrapped, and, like a good Samaritan, he went to release the animal; but, while he was in the act of doing so, the dog bit him on the middle finger of the left hand. From inquiries subsequently made, there was no evidence to show that any symptoms of madness had been exhibited by the animal before; hence the presumption is, that it had been induced by the pain caused by the trap, although the best authorities suppose, that rabies in the dog, and in animals of that class, originates only from contagion. (The end of the dog occurred four days afterwards, when he was found ten or twelve miles off, frothing at his mouth, evidently in a most rabid state, attacking a pony, afterwards snatching at trees, stone-posts, or anything which might be in his way, where he was shot.)

A considerable amount of blood flowed from the bitten finger; no medical advice was resorted to, only poultices applied for a few nights, and at the expiration of a week the wound was healed, a small cicatrix only remaining at the injured spot, with a considerable amount of numbness, which by and bye disappeared. His health seemed quite good until three weeks previously to his being visited professionally, when he was noticed to be apathetic, downcast, and desponding. While in church on Sunday, April 15th, where he held the office of parish clerk, he stopped abruptly in the middle of the response he was reading, and yawned, which symptom continued for several days; he also complained of pain in the finger, passing up the arm, and felt languid, with a sense of exhaustion. On Friday, April 20th, he had

* Read before the Northern Branch, June 22nd, 1866. occasion to go to Darlington, where he told me he felt so ill that he thought he would be unable to return home again, on account of languor; he, however, had a glass of beer there, (being a very temperate man) and returned to his abode in the evening, when he went to bed, taking nothing either in the shape of food or drink. Feeling very hot and restless, he took a diaphoretic, which acted so powerfully during the night as to make the bed-clothes completely saturated with perspiration. During the night he asked for tea and water, but only a few drops could be swallowed by him. Whenever any vessel containing liquid was put into his hands, he tried to quaff it off, but he was quite unable to do it, putting it aside with a sigh, saying, "he felt so tired he could take nothing." His wife slept in the same bed with him, whom, he said in the morning, he frequently felt disposed to bite through the night. He never closed his eyes that night, and was exceedingly sensitive to touch, especially about the neck.

When seen by my assistant the following morning (Saturday), nearly seven weeks from the time when he had been bitten, he was labouring under great mental excitement; he complained of pain in the hand, radiating up the arm, but nothing was visible to account for this; also, of a peculiar sinking sensation at the pit of the stomach, with slight constriction of the throat. There was no morbid appearance in the mouth or fauces, excepting the total absence of saliva, rendering these parts dry and clammy. His features had a peculiar wild expression, with dilated pupils, while the white of the eye was exceedingly brilliant, with a glassy appearance; there was a hanging down of the lower lip, especially visible when any fluid was offered him. His circulation was unaffected, but the respiration was peculiar, as it appeared almost to stop at times, then a sigh followed, sueceeded by a long expiration. He was now totally unable to drink any liquid; the sight of water excited, he said, "a peculiar sensation all over him." On its being proposed to him to drink, he said he would try ; but, so soon as the liquid touched his lips, he gave a convulsive sigh and threw back his head, calling out, "I cannot take it, sir, I cannot." He swallowed some jelly, which, however, caused some slight spasm, with a gurgling noise. An injection of several grains of morphia was administered, and blisters were applied on the spine, neck, and stomach. The patient was left for a few hours, until ten o'clock, when, on being seen, he expressed bimself as being relieved by the treatment, which was ordered to be repeated; he swallowed then a few drops of water with the same kind of noise as before.

My first visit was made to him about three o'clock in the afternoon. On entering his apartment, both window and door being open, I shut the window, which immediately produced in the poor sufferer a severe spasm of the muscles of the larynx and pharynx, throwing him into a state of the greatest agitation and alarm. His countenance had the same excited appearance as previously described; the pupils were much dilated; pulse 90 . On remaining a short time quietly at his bedside, I entered into conversation with him, (he being a person of considerable intelligence), when he gave me a full detail of his malady; at same time saying, he knew there was no remedy for his disease, of which he had read an account in medical books, (he being an herbalist) but he was wishful to use any means I thought might prove serviceable; on again examining his pulse, I found it had fallen to 60, and intermitted slightly. I offered him liquid in a cup, which he held in his hands, looking wistfully at it, but said he could not 
take it ; on pressing him, however, to do so, the constriction in the throat immediately came on. He lay down quietly in bed for a minute or so, pulling the clothes over him, and then suddenly sprang up, tossing his hands about in all directions, his eye roaming wildly through the room, like a chained fox. He told me not to touch him, also begged me not to allow his wife to sleep that night in the same bed with him, lest he should injure her. His mouth continued still very clammy. The disease was manifestly making greater inroad upon his frail body. On leaving him, I darkened the window; and, while I was crossing the room, he asked me to tread lightly, as the slightest noise made him worse; he also desired me to caution his friends in the house, who were numerous, not to speak aloud. I wished my assistant to have recourse to the use of ice, both externally along the spine, as well as internally ; also gave him one drop of croton oil, as his bowels were confined. I further recommended, at a later period, that, if there were no relief to the symptoms, chloroform should be inhaled, and the body nourished by enemata of beef-tea and opium. From some unexplained cause, the ice was not procured, and the patient was left until seven o'clock; and the statement then given was, that he had slept for above an hour, and, on awakening, expressed himself refreshed: but all the symptoms soon became worse. On being questioned how he felt, he said, "I am worse, worse. Its a queer sensation ; it rises up, and up." He now expressed a desire to see Dr. Mackintosh, of the Dinsdale Park Retreat, putting this question to the medical attendant present, "Had not the doctor great experience in nervous diseases." He was accordingly sent for, but, being from home, did not see the patient until midnight. Chloroform was now immediately resorted to; but, when he saw the bottle containing it, the symptoms became aggravated. He said, "Don't give me anything, it will make me go raving mad." The use of the remedy was, however, explained to him, when he quietly yielded, and inhaled the anæsthetic balm with a marked soothing influence. His mouth, which had hitherto been dry and parched, became speedily filled with saliva. He soon ate an orange, and stated he felt much relieved, and thought he would now be cured. He now fell asleep for above an hour, when he awoke feeling refreshed, and again expressed to his attendants the belief that he was going to be cured. Alas! however, he soon became more excited; shouting out, "Sing the Doxology, but sing it down stairs, for I cannot bear the least noise." He also asked his brother to pray with him, but not to be long over it, as he could not bear him speaking much. Paroxysms of excitement now came over him. He started up in bed, calling out "I am getting worse; it 's coming"; and sprang right out of bed into the middle of the room. Foaming saliva now flowed copiously from his mouth, which, with his hands, he flung all over the room. "Keep the door and windows fast, in case I commit suicide. What a wonderful cure it will be, if I get through." The paroxysms of suffering continued throughout the night, but towards morning he hecame quieter, and at about eight o'clock chloroform was again attempted to be made use of; but when the handkerchief came near him, he being now in bed, he quickly raised himself up, calling out, "Back, back, it's horrible; I feel it coming." There were now convulsive twitchings of the muscles of the face, with the angles of the mouth drawn slightly upwards, giving a somewhat risus sardonicus expression. A shuddering tremor came over him. The attempt to administer the chloroform was now abandoned, when he lay quietly down in bed, turning his head, however, from side to side, his eye wandering about in all directions. After a short time, the chloroform. was again attempted to be made use of ; but, ere ever it could get near him, he was seized with one of those spasms which caused him to leap out of bed, uttering a cry, as described to me, between a howl and a bark, running into a corner of the room, panting for breath, and in a state of awful horror; where he remained for some time, hawking, barking, and spitting, rested on his hands and knees. Whilst spitting this saliva, he said, "I'm bringing up the poison; I am getting rid of a deal of stuff." Being again asked to inhale the chloroform, he replied, "Wait a little, I have not done yet; there is more poison working down here in my stomach." The spitting, which had for a considerable time been large in quantity, now became scanty and watery. Chloroform was now assiduously administered for three hours, but signally failed to induce thorough anæsthesia. As he was becoming more excited, restraint was had recourse to, in the shape of fastening his hands to the bed; to which he offered no resistance, but said "Tie me fast, for I am a dangerous customer to work with." He now became very talkative, with considerable muttering and incoherent raving; when spoken to, however, he answered quite rationally. He said, "What a queer thing it is to be out of one's senses, and yet be sensible." In the early part of the afternoon, he continued snapping his teeth, hawking, and spitting; throwing his saliva all around. Peculiar noises were now heard in his throat, which were audible a considerable distance from the house. The expectoration now became changed in appearance; having been first thick and ropy, afterwards thin and watery, it now had quite a bloody cast, with at times great gushes of this gramous fluid issuing from his mouth and nostrils. His pulse now was so small as to be scarcely perceptible; but his strength was surpassing wonderful. Dr. Mackintosh again saw him about three o'clock in the afternoon, and administered to him a little rum and water; the first portion of which he swallowed with only a slight spasm, but the second portion threw him into a fearful paroxysm of agony. Having been prevented from seeing him earlier in the day, I visited him at four o'clock, when I found him almost pulseless, yet wonderfully strong, with his mind quite clear. He was busily engaged swallowing milk, which was almost instantly rejected on entering the stomach. He said to me, "It is going down easy ; it is keeping down inflammation." He then stated, "I shan't get over it, but I am prepared to die; but do all you can for me." The sight of fluid did not now disturb him. I am informed that, for three hours after I left, his sufferings were horrible; as he himself suid, "his agony was beyond description." Paroxysm followed paroxysm, until great drops of sweat covered his face and neck; the brows became contracted, with dilated nostrils and pupils, giving him an awful appearance. Chloroform had not the least effect upon him ; eleven ounces of which had up to this time been used. Soon after seven in the evening he became wonderfully calm, but quite pulseless; which state continued for two hours, when another paroxysm of suffering came on. He was now lying on his back, and said, "Farewell, gentlemen, I am dying, but I cannot die on my back, turn me over'; which on being done, he leaned over the side of the bed, gave one or two sighs, and expired.

A coroner's inquiry was held over the body, but no post mortem examination was obtained.

The treatment of this disease has hitherto been singularly unsatisfactory; but may be divided into prophylactic and curative. In the former, the chief thing to depend upon is, excision of the injured part; but if this from locality be impracticable, then the 
free use of the more powerful caustics, as strong nitric acid and potassa fusa. Some individuals remember when it was the practice, in England, to take person bitten by mad dogs to the sea-coast, and there immerse them in the briny main.

From the fact that few of those bitten by rabid animals actually contract hydrophobia, we should expect that a large number of specifics should have been vaunted as curative agents; and among these we find the famous Ormskirk medicine, the Tonquin medicine, and the Tanjore pills. Of late, the use of the hot-air and vapour bath has been highly applauded, not only as prophylactic, but also as curative. Dr. Buisson, of Lyons, states in a pamphlet of his, that he succeeded in curing himself when labouring under hydrophobia, by taking a bath at the temperature of $93 \mathrm{deg}$. Fahr., all the symptoms disappearing like magic. Furthermore, he adds that he has attended more than eighty persons bitten by mad animals, and that he has not lost a single case. The plan he adopts is this: "the person bitten by a mad dog takes a vapour bath for seven successive days, at a temperature ranging from $134 \mathrm{deg}$. to $145 \mathrm{deg}$. Fahr.; this being the preventive remedy. When the disease is declared, it only requires one vapour bath, rapidly increased to $88 \mathrm{deg}$. Fahr., then slowly to $145 \mathrm{deg}$., the patient confining himself to his room, until the cure is complete" (very simple, if true.)

Every means should be taken to tranquillise the mind and remove imaginary terror, as these are powerful exciting causes of the disorder; especially so when the person affected is aware that the animal from which the bite has been received is in a rabid state. Amongst the curative means it is still an undecided point, whether any interference should now be made with the cicatrix, as to being either excised or amputated. Injection of the vaccine virus has been tried, which has also failed; also the poison of the viper, injections of warm water into the veins, morphia, etc. Salivation by mercury has been proposed, and in America a case is said to have been cured in four days, after the use of four drachms and a half of calomel. A medical friend told me that he knew of an instance wherein a rabid dog had bitten twelve persous in a small locality; that mercury was had recourse to, and wherever salivation was induced, those recovered, amounting to eight, while the others died. Indian hemp, opium, etc., have been recommended. The late Professor Todd nearly cured a case with ice administered externally and intermally. Chloroform seems also to fail in giving relief to any grent extent. I fear that we must sum up the whole by saying, that the great Physician to cure, is death alone.

I may just add, in reference to the morbid anatomy, that in the most recent article on this disease, it is stated that there are no cadaveric lesions which can be said in any way to characterise hydrophobia. Most commonly there are found redness and swelling of the fauces and gullet, occasionally accompanied by enlargement of the salivary glands, and sometimes with redness of the stomach. The trachea and bronchi have often been found injected, and filled with frothy mucus. The lungs are congested, occasionally inflamed, sometimes empty and œdematous.

The brain has been found occasionally congested; sometimes there has been effusion into the arachnoid and lateral ventricles. The medulla oblongata, and the origins of the seventh, eighth, and ninth nerves, have been noticed to be congested, thickened, and softened. The pathology of the disease points to some peculiar alteration in the blood, affecting the nervous system, especially the medulla oblongata and three divisions of the eighth pair. The poison effects slowly some change in the blood; a double zymosis taking place, first in the bitten part, afterwards in the general system.

\section{CASE OF}

LIGATURE OF THE COMMON CAROTW ARTERY.*

By JOHN J. NASON, M.B., Surgeon to the Infirmary, Stratford-on-Avon.

ON September 29th, I was called into the country, a distance of two miles, to see a boy who had been stuck through the neck with a stable-fork, by a fellow servant. I found him lying on his left side on a mattress in the stable-yard. He was almost pulseless, and in a state of great collapse. The account given was, that he had been out to turn over manure with another boy; that a quarrel had ensued, and that the latter ran at him with a fork, and stuck him through the neck, pinning him to the wall. The injured boy ran screaming towards the garden, where he was met by two gardeners, just in time to save him from falling. Blood was streaming from his mouth, and a track of blood was observed from the garden to the manure-heap, a distance of thirty yards. Ex amining him, I found on the left side of the neck a horizontal wound, from three to four inches long, with slightly inverted edges; it was about an inch and a half below the angle of the jaw, and just over the course of the carotid artery. On the right side of the neck, was a darkish swelling, of about the size of half a lemon, having in its centre a darker blood-stained spot, which as nearly as possible corresponded in situation with the wound on the left side. From the situation of the external wound, from the great loss of blood-the blood coming principally from the mouth, denoting injury to the pharynx, from the continued ecchymosed swelling of the right side, and from his great collapse, I inferred that the carotid vessel or vessels had been wounded. For a time I was unable to feel pulsation in any of the branches given off by either carotid; but, after a time, I. could detect pulsation in the facial and temporal arteries of the right side, but not of the left. I summoned to my assistance my friend Dr. Rice, who agreed with me that the left carotid artery, just before the division, or the left internal carotid alone, or even in conjunction with the external carotid, had been wounded. The boy's state was one of great collapse; and, as it was doubtful whether the wounded vessel was the common carotid, or one or both of its chief divisions, and it was expedient to add as little more to the shock as possible, and to save every drop of blood, we resolved to tie the common carotid in the part most accessible, namely, in the lower part of the carotid triangle. The operation was performed without much difficulty, and without the loss of a drachm of blood; it was not followed by paralysis, or any untoward symptom. The ligature came away on the twelfth day, the wound gradually healed up, and the boy steadily progressed to convalescence, and has remained perfectly well ever since.

* Read before the Birmingham and Midland Counties Branch, on January 10th, 1867. 